\title{
REVISÃO SISTEMÁTICA DE ESTUDOS SOBRE COMPUTAÇÃO DESPLUGADA NA EDUCAÇÃO BÁSICA E SUPERIOR DE 2014 A 2020: Tendências no Campo
}

\author{
Sabrina Bourscheid Sassi ${ }^{1}$ \\ Cristiano Maciel $^{2}$ \\ Vinícius Carvalho Pereira ${ }^{3}$
}

\begin{abstract}
RESUMO
Este artigo tem como objetivo apresentar uma Revisão Sistemática da Literatura (RSL) de trabalhos científicos sobre Computação Desplugada (CD) na Educação Básica e no Ensino Superior, publicados de 2014 a 2020 em alguns dos principais meios acadêmicos brasileiros relacionados à Computação e Educação - SBIE, WIE, WCBIE, RBIE, Renote, WEI, WIT e Anped - de modo a mapear tendências no campo para futuras pesquisas. Para tanto, seguiram-se as etapas definidas no protocolo de pesquisa e a consulta às bases de dados eletrônicos. Dos estudos pesquisados foram selecionados para análise 67 que atenderam aos critérios de inclusão estabelecidos. Os principais resultados indicam que há um aumento nas pesquisas quanto ao uso da CD na Educação Básica, especialmente no Ensino Fundamental e em escolas públicas. A maior parte dos estudos baseia-se nas atividades do livro Computer Science Unplugged e em atividades desplugadas autorais. Os conceitos mais trabalhados nos estudos são Algoritmo, Lógica de Programação e Números Binários. A maioria dos trabalhos analisados são desenvolvidos sem associação explícita a alguma disciplina da Base Nacional Comum Curricular (BNCC).

Palavras-chave: Computação desplugada. Pensamento computacional. Revisão Sistemática da Literatura. Computação e educação. Base Nacional Comum Curricular. Educação básica. Educação superior.
\end{abstract}

\section{A SYSTEMATIC LITERATURE REVIEW OF STUDIES ON UNPLUGGED COMPUTING IN ELEMENTARY/HIGH SCHOOL AND HIGHER EDUCATION FROM 2014 TO 2020: TRENDS IN THE FIELD}

\begin{abstract}
The objective of this paper is to present a Systematic Literature Review (SLR) of scientific papers on Unplugged Computing (UC) in Elementary/High School and Higher Education, published from 2014 to 2020 in some of the main Brazilian academic communities related to Computer Sciences and Education - SBIE, WIE, WCBIE, RBIE, Renote, WEI, WIT and Anped - so as to map out trends in this field for future research. To do so, we followed the main research protocol steps and searched through the electronic databases. From all the studies we found, we selected sixty-seven that met our inclusion criteria. The main results show there is an increase in the number of research on the use of UC in Elementary/High School, mainly in Elementary School and public schools. Most studies are based on activities from the book Computer Science Unplugged and on independently developed unplugged activities. The most common concepts in those studies are Algorithm, Programming Logic, and Binary Numbers. Most studies are carried out without any explicit relation to subjects from the Base Nacional Curricular Comum (National Brazilian Common Syllabus).

Keywords: Unplugged computing. Systematic literature review. Computer science and education. National brazilian common syllabus. Elementary/high school and higher education.
\end{abstract}

RECEBIDO EM: 30/11/2020

ACEITO EM: 23/1/2021

\footnotetext{
1 Universidade Federal de Mato Grosso (IE-PPGE/UFMT/SEDUC-MT) - Cuiabá/MT, Brasil. http://lattes.cnpq.br/1298703127631330. https:// orcid.org/0000-0002-9979-882X.

2 Autor correspondente. Universidade Federal de Mato Grosso, Instituto de Computação (IC/IE-PPGE/UFMT). Av. Fernando Corrêa, no 2367, Boa Esperança - 78060900 - Cuiabá/MT, Brasil. http://lattes.cnpq.br/5234437367053668. https://orcid.org/0000-0002-2431-8457. crismac@gmail.com

3 Universidade Federal de Mato Grosso (IL-PPGEL/UFMT) - Cuiabá/MT, Brasil. http://lattes.cnpq.br/5304593788129950. https://orcid.org/ 0000-0003-1844-8084.
} 
O uso de tecnologias digitais tem se tornado cada vez mais presente em nossas vidas, seja para uso no trabalho, lazer ou estudos. Assim, tratar das tecnologias como ferramentas de ensino-aprendizagem tem sido inevitável, pois, além de serem recursos didáticos de grande impacto, também podem ser utilizadas como "forma de estruturar problemas e encontrar soluções para os mesmos, utilizando fundamentos da Computação (Pensamento Computacional)" (BRACKMANN, 2017, p. 20).

O Pensamento Computacional (PC) é definido por Wing (2010) como processos de pensamento envolvidos na formulação de um problema, que expressam solução(ões) de forma eficaz e podem ser realizados por uma máquina ou uma pessoa, mostrando-se tão importante para a vida na sociedade contemporânea quanto os conhecimentos básicos de Matemática, Filosofia, Biologia, entre outras áreas. A autora acrescenta que o PC é uma atividade mental, pode ser aprendido sem o uso de uma máquina e seu processo de pensamento mais importante e de alto nível é a capacidade de abstração.

Algumas convergências são identificadas entre a definição de PC e as habilidades relacionadas à Matemática (POLYA, 2004). Iniciativas visando à associação do PC a habilidades e conteúdos matemáticos têm sido mencionadas na literatura devido ao fato de que muitas habilidades a serem desenvolvidas nas diferentes áreas se interseccionam ou se complementam (BARCELOS; SILVEIRA, 2012). A integração do PC na Educação Básica ou Superior tem sido tratada dentro de seis abordagens, ${ }^{4}$ sendo uma delas a Computação Desplugada - CD (VALENTE, 2016).

Diante do exposto e na perspectiva de trazer uma contribuição para o debate acerca das produções acadêmicas sobre a Computação Desplugada nos Ensinos Básico e Superior, o presente trabalho propõe-se a uma Revisão Sistemática da Literatura (MORANDI; CAMARGO, 2015) de publicações científicas sobre o tema no período de 2014 a 2020. Para tanto, mapeamos e analisamos trabalhos nos eventos Workshop de Informática na Escola (WIE), Workshop sobre Educação em Computação (WEI), Workshop do Congresso Brasileiro de Informática na Educação (WCBIE), Simpósio Brasileiro de Informática na Educação (SBIE), Revista Novas Tecnologias na Educação (Renote), Revista Brasileira de Informática na Educação (RBIE), Women in Information Technology (WIT) e Associação Nacional de Pós-Graduação e Pesquisa em Educação (Anped) durante esse período, conforme critérios de inclusão e exclusão detalhados na seção Metodologia do presente artigo. Na análise, atentamos para o perfil do público-alvo destes estudos, as disciplinas que trabalharam a Computação Desplugada, os conceitos/conhecimentos que foram abordados/ensinados com o uso de Computação Desplugada e os recursos instrucionais e metodológicos utilizados. Em seguida, alguns pontos que envolvem o uso da Computação Desplugada na Educação Básica e Superior são sucintamente discutidos.

${ }^{4}$ Valente (2016) define seis categorias de abordagem no ensino de conceitos da Computação, sendo elas: atividades sem o uso de tecnologias; programação em Scratch; robótica pedagógica; produção de narrativas digitais; criação de jogos e uso de simuladores. 
O trabalho está estruturado da seguinte forma: na seção 2 é apresentado o conceito de computação desplugada; na seção 3 é descrita a metodologia usada neste trabalho; na seção 4 são apresentados os resultados obtidos e, por fim, na última seção, são apresentadas as considerações finais.

\section{COMPUTAÇÃO DESPLUGADA: APORTES PARA O ESTUDO}

O Pensamento Computacional tem sido integrado na Educação Básica e Superior por diferentes abordagens e, entre estas, uma não necessita do uso de tecnologias, equipamentos ou software específicos (VALENTE, 2016). Essa abordagem é definida na literatura como "Computação Desplugada" ou "Unplugged" e corresponde a atividades que envolvem a resolução de problemas para alcançar um objetivo e que também auxiliam na compreensão de conceitos fundamentais de Ciência da Computação, mas sem fazer uso de computador. Tais atividades podem ser aplicadas não somente para crianças, mas para todas as faixas etárias, desde o Ensino Fundamental até o Ensino Superior, proporcionando, dessa maneira, diferentes conhecimentos e experiências aos estudantes (BELL; WITTEN; FELLOWS, 2011).

A computação desplugada, além de possuir um objetivo científico, também tem cunho social, pois pode ser utilizada em diferentes lugares, sejam eles de difícil ou fácil acesso a tecnologias digitais, tornando o conhecimento básico da Ciência da Computação acessível aos menos favorecidos tecnologicamente (SILVA; SOUZA; MORAIS, 2016).

Para Brackmann (2017, p. 50), a abordagem desplugada “(...) introduz conceitos de hardware e software que impulsionam as tecnologias cotidianas a pessoas não técnicas". As atividades desplugadas possibilitam que o trabalho desenvolvido com os alunos ocorra, frequentemente, “(...) através da aprendizagem cinestésica (e.g. movimentar-se, usar cartões, recortar, dobrar, colar, desenhar, pintar, resolver enigmas, etc.) e os estudantes trabalham entre si para aprender conceitos da Computação".

Atualmente, muitos materiais de atividades desplugadas são disponibilizados na web de forma gratuita e têm uma grande aceitação e visibilidade, sobretudo com as diretrizes de currículo para o ensino de Computação no K-12 $2^{5}$ (CSTA, 2011). Como exemplo, podemos citar o site CS Unplugged (www.csunplugged.org), que dispõe de uma variedade de recursos gratuitos, incluindo o livro Computer Science Unplugged, aulas prontas para impressão de material, vídeos demonstrativos e material de apoio em diversos idiomas. Além do projeto Computer Science Unplugged, existem outros que visam à promoção do ensino da Ciência da Computação para crianças e jovens, tais como Code.org (2013), Programaê (2017) e Scratch (2017), que disponibilizam atividades plugadas e desplugadas. Ainda, projetos do Programa Meninas Digitais (MACIEL; BIM; DA SILVA FIGUEIREDO, 2018) têm utilizado estratégias de CD para demonstrar questões das áreas das tecnologias para meninas em áreas diversas, por exemplo, em oficinas na área de Interação Humano-Computador (MACIEL; BIM; BOSCARIOLI, 2012; AMARAL et al., 2015).

K-12 é a forma como os documentos oficiais nos Estados Unidos se referem à Educação Básica. 
As atividades voltadas para o ensino da Ciência da Computação que têm como abordagem a Computação Desplugada devem adotar como filosofia a busca pela simplicidade (as regras podem ser explicadas rapidamente), o engajamento (a atividade deve ser atraente para os alunos) e a cooperação ou competição (os alunos devem ser motivados a trabalhar em busca de uma meta) (BELL; WITTEN; FELLOWS, 2011).

Nesta seção foram apresentados elementos principais sobre a Computação Desplugada, mas não de forma exaustiva, visto que, no decorrer da demonstração dos resultados da Revisão Sistemática, essa temática será abordada em detalhes.

\section{METODOLOGIA}

A presente pesquisa faz uma revisão sistemática da literatura com base em estudos secundários, isto é, artigos científicos que abordam o tema Computação Desplugada. Tivemos como objetivo levantar informações do que já foi pesquisado, como foram realizadas estas pesquisas, quais resultados foram encontrados e, com base nisso, identificar tendências nos estudos sobre este tema no Brasil. O método de Revisão Sistemática da Literatura (RSL) é definido por Morandi e Camargo (2015, p. 142) como estudos secundários utilizados para

[...] mapear, encontrar, avaliar criticamente, consolidar e agregar os resultados de estudos primários relevantes acerca de uma questão ou tópico de pesquisa específico, bem como identificar lacunas a serem preenchidas, resultando em um relatório coerente ou em uma síntese.

Esta RSL segue as diretrizes propostas por Castro (2001), num processo de sete etapas: formulação da(s) pergunta(s); localização e seleção dos estudos; avaliação crítica dos estudos; coleta de dados; análise e representação dos dados e interpretação dos resultados, conforme apresentado nos próximos tópicos. Até o presente momento foram desenvolvidas seis etapas da RSL, enquanto a etapa de aperfeiçoamento e atualização refere-se à continuidade do estudo, a ser realizada posteriormente, quando nos dedicaremos ao mapeamento de lacunas no campo identificado por esta RSL.

\section{O protocolo da pesquisa}

No primeiro momento da RSL foi elaborado o protocolo da pesquisa, sendo definido o objetivo do estudo e as questões norteadoras, as estratégias de busca e a seleção dos estudos secundários (artigos completos e resumidos). Posteriormente foram determinados a fonte de busca, os critérios de inclusão e exclusão e os descritores de busca destes estudos.

A RSL aqui descrita apresenta um levantamento das pesquisas sobre a utilização da Computação Desplugada como abordagem para o ensino, realizadas no período de 2014 a 2020 e publicadas nos anais dos eventos WIE, WEI, WCBIE, SBIE, Renote, RBIE, WIT e Anped. Com a realização da RSL, propõe-se responder às seguintes perguntas: Qual o perfil do público-alvo destes estudos? Quais disciplinas estão trabalhando a Computação Desplugada? Quais conceitos são abordados/ensinados por meio da Computação Desplugada? Quais recursos instrucionais e estratégias de ensino/aprendizagem estão sendo utilizados no ensino com Computação Desplugada? 
Com o objetivo de analisar um determinado espaço de pesquisa no cenário nacional, foram empregados os seguintes descritores nos idiomas Português e Inglês: "computação desplugada", "informática desplugada", "atividades desplugadas", "unplugged activities", "computer science unplugged", "unplugged class". Tais termos deveriam constar ao longo dos artigos a serem incluídos na revisão.

A estratégia de busca utilizada nesta revisão inclui apenas bases de dados eletrônicos como fontes de pesquisa. As publicações revisadas por esta pesquisa são dos últimos seis anos (entre 2014 e 2020) nas principais bases nacionais científicas relacionadas à Informática na Educação, à Educação em Computação e a pesquisas de Pós-Graduação Stricto Sensu em Educação, conforme mostra o Quadro 1:

Quadro 1 - Fonte de Pesquisa de Publicações Nacionais

\begin{tabular}{|l|l|}
\multicolumn{1}{c|}{ SIGLA } & \multicolumn{1}{c|}{ FONTE } \\
\hline WIE & Workshop de Informática na Escola \\
\hline WEI & Workshop sobre Educação em Computação \\
\hline WCBIE & Workshops do Congresso Brasileiro de Informática na Educação \\
\hline SBIE & Simpósio Brasileiro de Informática na Educação \\
\hline RENOTE & Revista Novas Tecnologias na Educação \\
\hline RBIE & Revista Brasileira de Informática na Educação \\
\hline WIT & Women in Information Technology \\
\hline ANPED & Associação Nacional de Pós-Graduação e Pesquisa em Educação \\
\hline
\end{tabular}

Fonte: Elaborado pelos autores.

Para a seleção dos estudos foram determinados critérios de inclusão (quatro critérios) e exclusão de estudos (seis critérios), definidos com base no escopo da revisão, conforme apresentado no Quadro 2.

Quadro 2 - Critérios de Inclusão e Exclusão dos Estudos

\section{Critérios de Inclusão}

- Publicações entre 2014 e 2020;

-Trabalhos escritos em Língua Portuguesa ou Língua Inglesa;

- Artigos completos ou resumidos;

- Trabalhos que citam o uso de Computação Desplugada ao longo do artigo.

\section{Critérios de Exclusão}

-Publicações em idiomas diferentes de Português e/ou Inglês

- Publicações sem acesso livre em bibliotecas digitais;

- Publicações fora do período de 2014 a 2020;

- Trabalhos não relacionados à Computação Desplugada;

- Trabalhos duplicados e/ou com versão de publicação mais recente ou mais completa;

- Documentos disponíveis na forma de estudos secundários (revisão sistemática da literatura e/ou mapeamentos sistemáticos), resumo, apresentação (pôster/painel), capítulo de livros sem resumo ou artigo sem vínculo com periódico ou conferência. 
A partir da definição das questões norteadoras, dos descritores, das fontes de pesquisa e dos critérios de inclusão e exclusão, realizou-se a busca e o processo de seleção preliminar e final das pesquisas, objetivando responder às questões-problema, conforme descrição apresentada a seguir.

\section{A coleta de dados}

A estratégia de busca pelos estudos abrange apenas bases nacionais de dados eletrônicos como fontes de pesquisa (os anais dos eventos WIE, WEI, WCBIE, SBIE, Renote, RBIE, WIT e Anped), consultadas em ordem cronológica de publicação. Embora estas bases permitam a busca automática (por meio de strings), decidimos nesta primeira fase realizar a busca manual extensiva por meio de leitura de título de todos os artigos publicados nos anais no período de 2014 a 2020, identificando os descritores definidos. Caso algum dos descritores supracitados constasse no título, o artigo era incluído em nossa amostra. Diante de estudos que não apresentassem algum dos descritores no título, passamos para a busca ao longo do artigo. Caso encontrado algum dos descritores no corpo do artigo, este também era incluído em nossa amostra.

Na primeira fase da revisão foram selecionados 77 estudos que atenderam aos descritores. Dos estudos selecionados, 75 atenderam aos demais critérios de inclusão e foram armazenados para a fase seguinte; 2 estudos foram excluídos por serem RSL.

O estudo de RSL de Santos et al. (2018) mapeou pesquisas nacionais que abordassem a CD publicadas entre os anos de 2012 e 2018, nas seguintes fontes: Renote, RBIE, SBIE, WIE, WCBIE e WEI. Foram selecionados e analisados pelos autores 15 artigos, atentando aos seguintes questionamentos: Em quais níveis de ensino estava sendo aplicada a computação desplugada? Como as atividades de computação desplugada estavam sendo realizadas? E como estas pesquisas estavam sendo avaliadas? Os resultados indicaram que a maioria dos estudos têm sido conduzidos no contexto do Ensino Fundamental, com a mesma escolha de material didático, o Computer Science Unplugged, e com avaliações qualitativas dos resultados obtidos.

O estudo de Rodrigues, Aranha e Silva (2018), também uma RSL, teve como objetivo fornecer um panorama da utilização da CD como abordagem para o ensino de programação no Brasil, considerando estudos publicados entre os anos de 2013 e 2017 nas seguintes fontes: SBIE, WIE, WCBIE, RBIE, SBGAMES, ${ }^{6}$ Renote e WEI. Para tanto, os pesquisadores buscaram descrever o público-alvo, a motivação, os materiais e métodos, os conteúdos, as estratégias de avaliação do aprendizado, bem como as possíveis vantagens e/ou limitações. Foram selecionados 20 artigos, primeiramente avaliados quanto à sua qualidade, para garantir que tivessem uma contribuição relevante para a RLS. A revisão não apresenta os resultados de forma sistematizada.

Diante do exposto, observa-se que as duas revisões diferem da RSL que ora apresentamos quanto aos objetivos, às questões norteadoras, a algumas fontes de pesquisa e à forma de busca pelos estudos.

https://www.sbgames.org/sbgames2018/anais 
A segunda fase desta revisão consistiu na leitura integral dos 75 estudos, dos quais se extraiu os seguintes dados para a análise: ano de publicação; instituição (pública ou privada); região do país; nível de ensino do público-alvo; disciplinas que trabalharam com a Computação Desplugada; conceitos/conhecimentos abordados/ensinados com o uso de Computação Desplugada; recursos instrucionais e metodológicos utilizados. A terceira fase da revisão compreendeu a análise e a interpretação dos dados. A sumarização dos dados constituiu a quarta fase, em razão do objetivo da revisão e dos critérios de seleção dos estudos.

A fase de aperfeiçoamento e atualização será realizada nos próximos anos, diante da necessidade de estarmos inteirados das tendências contemporâneas de pesquisa diante do tema Computação Desplugada.

\section{RESULTADOS}

Com o objetivo de apresentar os resultados desta revisão, organizamos os dados de acordo com as questões previamente definidas. Os 75 estudos selecionados foram identificados por sequência numérica, conforme ordem de busca por fonte e ano, com vistas à organização e à identificação no Quadro 3.

Quadro 3 - Relação dos estudos selecionados

\begin{tabular}{|c|c|c|c|}
\hline ID & AUTOR (ES) & ANO & FONTE \\
\hline 1 & (BEZERRA, 2014) & \multirow[b]{2}{*}{2014} & \multirow{3}{*}{ WIE } \\
\hline 2 & (SILVA; ARAUJO; ARANHA, 2014) & & \\
\hline 3 & (CAMPOS et al., 2014) & & \\
\hline 4 & (FERREIRA et al., 2015) & \multirow{3}{*}{2015} & \multirow{23}{*}{ WIE } \\
\hline 5 & (HINTERHOLZ; CRUZ, 2015) & & \\
\hline 6 & (SANTOS et al., 2015) & & \\
\hline 7 & (PINHO et al., 2016) & 2016 & \\
\hline 8 & (SILVA; SILVA; FRANÇA, 2017) & \multirow[t]{2}{*}{2017} & \\
\hline 9 & (ALVES et al., 2017) & & \\
\hline 10 & (MEDEIROS et al., 2018) & \multirow[t]{2}{*}{2018} & \\
\hline 11 & (REIS et al., 2018) & & \\
\hline 12 & (RODRIGUES; BRAGA; AMORIM, 2019) & \multirow{15}{*}{2019} & \\
\hline 13 & (SILVA; GUIMARÃES; JUNIOR, 2019) & & \\
\hline 14 & (BARROSO; SANTOS; MACHADO, 2019) & & \\
\hline 15 & (SANTOS; NUNES, 2019) & & \\
\hline 16 & (MELGAÇO; DIAS, 2019) & & \\
\hline 17 & (CASTILHO; GREBOGY; SANTOS, 2019) & & \\
\hline 18 & (LOPES; OHASHI, 2019) & & \\
\hline 19 & (SILVA et al., 2019) & & \\
\hline 20 & (BERARDI et al., 2019) & & \\
\hline 21 & (PEREIRA; ARAÚJO; BITTENCOURT, 2019) & & \\
\hline 22 & (FARIAS et al., 2019) & & \\
\hline 23 & (GERALDES; MARTINS; AFONSECA, 2019) & & \\
\hline 24 & (SANTANA; PEREIRA, 2019) & & \\
\hline 25 & (GUARDA; GONÇALVES; CUNHA, 2019) & & \\
\hline 26 & (WERLICH et al., 2019) & & \\
\hline
\end{tabular}




\begin{tabular}{|c|c|c|c|}
\hline 27 & (KOHLER et al., 2019a) & \multirow{4}{*}{2020} & \multirow{18}{*}{ WEI } \\
\hline 28 & (SIMAS; MOTTA, 2019) & & \\
\hline 29 & (FIGUEIREDO et al., 2020) & & \\
\hline 30 & (SILVA et al., 2020) & & \\
\hline 31 & (MARTINHAGO et al., 2014) & 2014 & \\
\hline 32 & (BARBOSA et al., 2015) & \multirow{2}{*}{2015} & \\
\hline 33 & (ARAÚJO et al., 2015) & & \\
\hline 34 & (RAIOL et al., 2016) & 2016 & \\
\hline 35 & (MARQUES; SOUZA; MOMBACH, 2017) & \multirow{2}{*}{2017} & \\
\hline 36 & (SANTOS; VERA; MATOS, 2017) & & \\
\hline 37 & (SILVA; GUARDA; GOULART, 2018) & \multirow{3}{*}{2018} & \\
\hline 38 & (RODRIGUES; LOPES, 2018) & & \\
\hline 39 & (MARINHO et al., 2018) & & \\
\hline 40 & (SANTANA; ARAÚJO; BITTENCOURT, 2019) & \multirow{3}{*}{2019} & \\
\hline 41 & (SILVA; SANTOS; ORLEANS, 2019) & & \\
\hline 42 & (PINHEIRO et al., 2019) & & \\
\hline 43 & (SASSI; MACIEL; PEREIRA, 2020) & \multirow{2}{*}{2020} & \\
\hline 44 & (LOPES; SANTANA; BRAGA, 2020) & & \\
\hline 45 & (BRACKMANN et al., 2017) & \multirow[t]{2}{*}{2017} & WCBIE \\
\hline 46 & (SILVA; FRANCO; JUNIOR, 2017) & & \\
\hline 47 & (SOUSA et al., 2018) & \multirow{4}{*}{2018} & \\
\hline 48 & (WERLICH et al., 2018) & & \\
\hline 49 & (LIMA et al., 2018) & & \\
\hline 50 & (COSTA; AZEVEDO; MADEIRA, 2018) & & \\
\hline 51 & (MARQUES; CRUZ; SCHULZ, 2019) & \multirow{3}{*}{2019} & \\
\hline 52 & (SILVA; GUARDA, 2019) & & \\
\hline 53 & (FRANÇA; TEDESCO, 2019) & & \\
\hline 54 & (KOLOGESKI et al., 2019) & \multirow{7}{*}{2019} & \multirow{7}{*}{ WCBIE } \\
\hline 55 & (GALVÃO et al., 2019) & & \\
\hline 56 & (SILVA et al., 2019b) & & \\
\hline 57 & (BULCÃO et al., 2019) & & \\
\hline 58 & (KOHLER et al., 2019b) & & \\
\hline 59 & (PIRES et al., 2019) & & \\
\hline 60 & (MARQUIORI; OLIVEIRA, 2019) & & \\
\hline 61 & (RODRIGUES; SAUSA, 2017) & 2017 & \multirow{7}{*}{ SBIE } \\
\hline 62 & (SOUZA; LOPES, 2018) & \multirow{3}{*}{2018} & \\
\hline 63 & (SILVA; CAVALCANTI, 2018) & & \\
\hline 64 & (CUNHA; NASCIMENTO, 2018) & & \\
\hline 65 & (BULHÕES et al., 2019) & 2019 & \\
\hline 66 & (MEDEIROS, 2020) & \multirow[t]{2}{*}{2020} & \\
\hline 67 & (SANTOS; SANTANA; PEREIRA, 2020) & & \\
\hline 68 & (KOSCIANSKI; GLIZT, 2017) & 2017 & \multirow{4}{*}{ RENOTE } \\
\hline 69 & (MOREIRA; MONTEIRO, 2018) & 2018 & \\
\hline 70 & (CREMA et al., 2019) & 2019 & \\
\hline 71 & (DALL AGNOL; GUSBERTI; BERTAGNOLLI, 2020) & 2020 & \\
\hline 72 & (BERTO; ZAINA; SAKATA, 2019) & 2019 & RBIE \\
\hline 73 & (AMIN et al., 2019) & \multirow[t]{2}{*}{2019} & \multirow{3}{*}{ WIT } \\
\hline 74 & (BIM et al., 2019) & & \\
\hline 75 & (PASSOS et al., 2020) & 2020 & \\
\hline
\end{tabular}

Fonte: Bases de dados dos eventos. Elaborado pelos autores. 
Como primeira atividade os 75 estudos foram organizados visando a uma análise do contexto destas pesquisas. Neste quesito, verificou-se a distribuição anual dos estudos, os eventos responsáveis pelas publicações e a região em que as pesquisas foram realizadas.

Ao observar a distribuição anual dos estudos apresentados no Quadro 3, identificamos que há um aumento considerável no número de estudos realizados e publicados entre os anos de 2017 e 2019, mostrando uma tendência crescente de pesquisas/publicações sobre o uso da Computação Desplugada em contextos de ensino-aprendizagem. No ano de 2020, porém, identificamos uma queda nas publicações, que pode ser reflexo ao contexto da pandemia vivenciado no Brasil.

No Quadro 3 a frequência das produções publicadas nos eventos é apresentada. Ao observá-la, percebe-se que há uma predominância de 40\% (30 dos 75) das publicações relacionadas à Computação Desplugada no Workshop de Informática na Escola (WIE), seguidas dos Workshops do Congresso Brasileiro de Informática na Educação (WCBIE), com presença de 21\% (16 dos 75), e do Workshop sobre Educação em Computação (WEI), com 18,6\% (14 dos 75).

Os eventos WIE, WCBIE e WEI são realizados anualmente pela Sociedade Brasileira de Computação (SBC) e têm como objetivo debater, propor avanços e soluções e divulgar pesquisas desenvolvidas na área da educação com foco na aplicação das Tecnologias Digitais de Informação e Comunicação (TDIC) em ambiente educacional.

Quanto à distribuição dos estudos, identificamos que foram realizados em 18 Estados brasileiros, das cinco regiões geográficas, conforme pode ser observado na Tabela 1. Observa-se que, dos 75 estudos, o maior número de pesquisas ocorreu na região Nordeste, seguida das regiões Sul e Sudeste. Cabe salientar que, das pesquisas na região Centro-Oeste (1 dos 10) foi realizada no Estado de Mato Grosso, concentrando-se o maior número no Distrito Federal ( 6 dos 10); 2 dos 10 foram realizados em Goiás e 1 dos 10 no Mato Grosso do Sul. Além disso, damos destaque a um estudo (BRACKMANN et al., 2017) que foi realizado na Espanha, apresentando parte dos resultados de uma pesquisa de Doutorado em Informática na Educação.

Tabela 1 - Distribuição dos estudos por região

\begin{tabular}{c|c|c}
\hline Região & Produção & Frequência \\
\hline Norte & $1 ; 13 ; 18 ; 30 ; 34 ; 47 ; 56 ; 59 ;$ & 8 \\
& & \\
\hline Sul & $3 ; 5 ; 6 ; 7 ; 9 ; 17 ; 20 ; 26 ; 27 ; 35 ; 48 ; 51 ; 54 ; 58 ; 68 ; 70 ; 71 ; 73 ;$ & 18 \\
\hline Nordeste & $2 ; 4 ; 8 ; 10 ; 15 ; 16 ; 21 ; 22 ; 24 ; 32 ; 33 ; 36 ; 38 ; 39 ; 40 ; 46 ; 50 ;$ & 26 \\
\hline Centro-Oeste & $53 ; 55 ; 57 ; 62 ; 63 ; 64 ; 66 ; 67 ; 69 ;$ & 10 \\
\hline Sudeste & $12 ; 14 ; 23 ; 25 ; 37 ; 43 ; 44 ; 49 ; 52 ; 61 ;$ & 12 \\
\hline
\end{tabular}

Fonte: Elaborado pelos autores.

Quanto ao perfil do público-alvo dos estudos selecionados na RSL, foi identificado que, em $81,3 \%$ dos estudos (61 dos 75), os participantes pertencem à escola pública, como pode ser observado na Tabela 2 . Além disso, destacamos que apenas dois estudos 
(53) e (74) não foram aplicados em ambiente educacional formal, um foi aplicado em um evento (14), um estudo não foi aplicado (66) e um não descreveu em qual rede de ensino foi aplicado (75).

Tabela 2 - Demonstrativo por Rede de Ensino

\begin{tabular}{c|l|c}
\hline Rede de Ensino & \multicolumn{1}{|c|}{ Produção } & Frequência \\
\hline & $1 ; 2 ; 3 ; 4 ; 5 ; 6 ; 7 ; 8 ; 9 ; 10 ; 13 ; 15 ; 16 ; 17 ; 18 ; 19 ; 20 ; 21 ; 22 ; 23 ;$ & \\
Pública & $24 ; 27 ; 28 ; 29 ; 30 ; 31 ; 32 ; 33 ; 34 ; 35 ; 36 ; 38 ; 39 ; 40 ; 41 ; 42 ; 43 ;$ & 61 \\
& $44 ; 45 ; 46 ; 47 ; 49 ; 50 ; 51 ; 55 ; 56 ; 57 ; 58 ; 59 ; 60 ; 61 ; 62 ; 63 ; 65 ;$ & \\
& $67 ; 68 ; 69 ; 70 ; 71 ; 72 ; 73 ;$ & 7 \\
\hline Privada & $11 ; 25 ; 26 ; 37 ; 48 ; 52 ; 64 ;$ & 2 \\
\hline
\end{tabular}

Fonte: Elaborado pelos autores.

Já o nível de ensino (ex. Educação Infantil, Ensino Fundamental I, etc.) pôde ser identificado em 71 estudos; 2 deles $(12 ; 53)$ não delimitaram a etapa do Ensino Fundamental na qual foram aplicados, e em outros $2(14 ; 61)$ não foi possível qualquer identificação do nível de ensino. Observa-se na Tabela 3 que alguns estudos conduziram suas intervenções em mais de um nível de ensino (abordagem mista), representando $14,6 \%$ (11 dos 75) dos estudos.

Em 68\% dos estudos (51 dos 75), o público participante das intervenções é constituído por alunos do Ensino Fundamental; em 24\% (18 dos 75), por alunos do Ensino Médio (considerando as abordagens mistas). O Ensino Superior e a Educação Infantil foram níveis de ensino com menor índice de intervenção, respectivamente, $12 \%$ (9 dos 75) e 1,3\% (1 dos 75). Os resultados indicam um maior interesse dos estudos que abordam Computação Desplugada ainda na Educação Básica (Educação Infantil, Ensino Fundamental e Ensino Médio), com uma representatividade de $86 \%$ dos estudos (65 dos 75 ) analisados.

Tabela 3 - Níveis de ensino

\begin{tabular}{|c|c|c|}
\hline Níveis & Estudos & Frequência \\
\hline Educação Infantil & 9 & 1 \\
\hline Ensino Fundamental I & $\begin{array}{l}3 ; 6 ; 7 ; 17 ; 22 ; 26 ; 27 ; 42 ; 48 ; 50 ; 55 ; 57 ; 58 ; 62 ; \\
64 ; 66 ; 67 ; 68 ; 72\end{array}$ & 19 \\
\hline Ensino Fundamental II & $\begin{array}{l}1 ; 10 ; 11 ; 13 ; 15 ; 19 ; 21 ; 25 ; 28 ; 33 ; 34 ; 38 ; 40 ; 44 ; \\
46 ; 52 ; 54 ; 60 ; 74 ; 75\end{array}$ & 20 \\
\hline Ensino Fundamental I e II & $18 ; 29 ; 37 ; 41 ; 45$ & 5 \\
\hline Ensino Fundamental & $12 ; 53$ & 2 \\
\hline Ensino Fundamental e Médio & $4 ; 23 ; 36 ; 43 ; 56$ & 5 \\
\hline Ensino Médio & $5 ; 20 ; 24 ; 32 ; 39 ; 59 ; 63 ; 70 ; 73$ & 9 \\
\hline Ensino Médio Técnico & $16 ; 35 ; 65$ & 3 \\
\hline Ensino Médio e Superior & 49 & 1 \\
\hline Ensino Superior & $2 ; 8 ; 30 ; 31 ; 47 ; 51 ; 69 ; 71$ & 8 \\
\hline Não identificou nível & $14 ; 61$ & 2 \\
\hline
\end{tabular}

Fonte: Elaborada pelos autores.

Essa maior abordagem de a CD ocorrer na Educação Básica pode ser justificada com a reformulação da Base Nacional Comum Curricular (BNCC), que é o documento que orienta a gestão pedagógica brasileira e define os conhecimentos essenciais, dentro dos componentes curriculares, aos quais os estudantes têm direito de ter acesso e 
se apropriar durante toda sua trajetória escolar (BRASIL, 2020). Entre as diversas propostas previstas estão o Pensamento Computacional (PC) e alguns conceitos correlatos, como Cultura Digital, Tecnologias Digitais da Informação e da Comunicação (TDIC), Redes Sociais, Algoritmos, etc.

Em paralelo, a Computer Science Teachers Association (CSTA), a National Science Foundation (NSF) e a International Society for Technology in Education (Iste) desenvolveram, em conjunto, o material Computational Thinking in K-12 Education Leadership Toolkit, que orienta o ensino da Computação nas escolas da Educação Infantil até o Ensino Médio, propondo que os alunos ao final da Educação Básica devem demonstrar habilidades essenciais para resolução de problemas com base nos fundamentos e técnicas da Ciência da Computação (CSTA; ISTE, 2011). Tal proposta, que revela não só concepções acerca do uso pedagógico da $C D$, mas também de questões de currículo, está em consonância com os números de estudos na Educação Básica.

Também buscamos identificar nos estudos como a Computação Desplugada vem sendo trabalhada em diferentes contextos de ensino-aprendizagem, e organizamos na Tabela 4 os estudos com base nas disciplinas e na frequência em que a CD foi empregada.

Tabela 4 - Disciplinas que estão trabalhando com Computação Desplugada

\begin{tabular}{|c|c|c|}
\hline Disciplinas & Estudos & Frequência \\
\hline Matemática & $9 ; 11 ; 25 ; 37 ; 40 ; 57 ; 75$ & 7 \\
\hline Português & 10 & 1 \\
\hline Inglês & 43 & 1 \\
\hline Matemática e Português & 15 & 1 \\
\hline Computação, Matemática e Português & 14 & 1 \\
\hline Português, Matemática e Geografia & 50 & 1 \\
\hline $\begin{array}{l}\text { Português, Matemática, Química, Arte, Bio- } \\
\text { logia e Educação Física }\end{array}$ & 4 & 1 \\
\hline $\begin{array}{l}\text { Português, Matemática, Filosofia, Ciências, } \\
\text { História, Biologia e Inglês }\end{array}$ & 36 & 1 \\
\hline Informática & 5 & 1 \\
\hline Introdução à Computação & 1 & 1 \\
\hline Estágio & 8 & 1 \\
\hline Redes de Computadores & 16 & 1 \\
\hline Banco de Dados & $30 ; 31$ & 2 \\
\hline Estrutura de Dados & 69 & 1 \\
\hline Programação I & 35 & 1 \\
\hline Algoritmo I & 49 & 1 \\
\hline Pensamento Computacional & $26 ; 48$ & 2 \\
\hline Atividades de contraturno & $\begin{array}{c}2 ; 3 ; 6 ; 7 ; 12 ; 13 ; 17 ; 18 ; 19 ; 20 ; 21 ; 22 ; \\
23 ; 24 ; 27 ; 28 ; 2932 ; 33 ; 34 ; 38 ; 39 ; 41 ; \\
42 ; 4445 ; 46 ; 47 ; 51 ; 52 ; 53 ; 54 ; 55 ; 56 ; \\
58 ; 59 ; 60 ; 61 ; 62 ; 63 ; 64 ; 65 ; 66 ; 67 ; 68 ; \\
\quad 70 ; 71 ; 72 ; 73 ; 74\end{array}$ & 50 \\
\hline
\end{tabular}

Fonte: Elaborada pelos autores.

Observando os dados apresentados na Tabela 4, o que chama a atenção é a não vinculação da Computação Desplugada com alguma disciplina da Base Nacional Comum Curricular em $66 \%$ dos estudos (50 dos 75). Nos 50 estudos, o desenvolvimento das atividades desplugadas ocorreu no contraturno das aulas, como atividade extraclasse. 
Em 11 estudos a CD foi empregada em disciplinas da Área da Computação. Quanto às disciplinas previstas na Base Nacional Comum Curricular (BNCC), 14 estudos relacionaram pelo menos uma disciplina, com destaque para a Matemática, que está presente em 12 trabalhos, 7 deles exclusivamente vinculados a essa disciplina. Foi observada a interdisciplinaridade em 3 estudos $(4 ; 14 ; 15)$, estando a Matemática relacionada com Português, ou Química, ou Biologia.

Em relação aos conceitos abordados/ensinados por meio da CD nos estudos analisados, destacam-se três por ordem decrescente de ocorrência: Algoritmo, Lógica de Programação e Números Binários, conforme relacionado na Tabela 5.

Tabela 5 - Conceitos abordados/ensinados

\begin{tabular}{|c|c|c|}
\hline Conceitos & Estudos & Frequência \\
\hline Números Binários & $\begin{array}{c}4 ; 5 ; 11 ; 13 ; 14 ; 15 ; 18 ; 19 ; 20 ; 21 ; 32 ; 33 \\
38 ; 40 ; 41 ; 42 ; 63 ; 64 ; 65 ; 68 ; 74 ;\end{array}$ & 21 \\
\hline Pensamento Computacional & $\begin{array}{c}8 ; 17 ; 25 ; 26 ; 27 ; 28 ; 44 ; 46 ; 53 ; 54 ; 57 ; 58 ; \\
60 ; 66 ; 67 ; 71 ; 72 ; 74 ;\end{array}$ & 18 \\
\hline Criptografia & $2 ; 12 ; 14 ; 37 ; 51 ; 52 ; 74$ & 7 \\
\hline Algoritmo & $\begin{array}{c}1 ; 4 ; 6 ; 7 ; 14 ; 15 ; 19 ; 21 ; 24 ; 29 ; 32 ; 40 ; 41 ; \\
42 ; 43 ; 45 ; 47 ; 49 ; 51 ; 55 ; 56 ; 58 ; 59 ; 61 ; 63 \\
68 ; 70 ; 72 ; 73 ; 74\end{array}$ & 30 \\
\hline Detecção e Correção de Erro & $2 ; 14 ; 21 ; 41 ; 61$ & 5 \\
\hline Abstração e Representação de Dados & $1 ; 3 ; 7 ; 10 ; 14 ; 19 ; 20 ; 31 ; 45 ; 47 ; 51 ; 55 ; 58$ & 13 \\
\hline Banco de Dados & $5 ; 20 ; 30 ; 31$ & 4 \\
\hline Lógica de Programação & $\begin{array}{l}4 ; 7 ; 9 ; 13 ; 15 ; 22 ; 23 ; 24 ; 33 ; 35 ; 36 ; 37 ; 39 ; \\
46 ; 48 ; 54 ; 58 ; 59 ; 61 ; 62 ; 69 ; 70 ;\end{array}$ & 22 \\
\hline Representação de Imagens & $18 ; 21 ; 33 ; 36 ; 40 ; 41 ; 68 ; 74 ; 75$ & 9 \\
\hline Software & $21 ; 36 ; 39$ & 3 \\
\hline Componentes de Hardware & $21 ; 36 ; 39 ; 40 ; 51 ;$ & 5 \\
\hline Evento (Programação) & $14 ; 50$ & 2 \\
\hline Linguagem de Blocos & $21 ; 22$ & 2 \\
\hline Segurança WEB & 12 & 1 \\
\hline Redes de Computadores & $16 ; 36 ; 41 ;$ & 3 \\
\hline Educação em Computação & 34 & 1 \\
\hline Redes Sociais & 36 & 1 \\
\hline
\end{tabular}

Fonte: Elaborada pelos autores.

Os estudos apresentaram em suas descrições os conceitos da Computação trabalhados com atividades plugadas e desplugadas. Quanto aos conceitos, $49,3 \%$ dos estudos (37 dos 75) trabalharam apenas um conceito, $28 \%$ dos estudos ( 21 dos 75 ) trabalharam dois conceitos, 13,3\% (10 dos 75) trabalharam três conceitos, 4\% (3 dos 75) trabalharam quatro conceitos, 1,3\% (1 dos 75) trabalhou cinco conceitos, 2,5\% (2 dos 75 ) trabalharam seis conceitos e $1,3 \%$ (1 dos 75) trabalhou sete conceitos em um único estudo. Observa-se que há uma predominância em estudos com até três conceitos sendo trabalhados com os alunos. O estudo (36) que apresenta um maior número de conceitos abordados/ensinados na experiência corresponde a uma intervenção realizada com professores que atuam em diferentes áreas, sendo elaborado um plano de aula para cada professor com o objetivo de ensinar o conteúdo programático da disciplina junto a um conteúdo de Computação. 
Na sequência, nossa pesquisa concentrou-se na busca por estudos que abordassem a computação desplugada. Dos 75 estudos analisados, 69,3\% (52 dos 75) abordaram apenas a computação desplugada e 30,7\% (23 dos 75) utilizaram computação plugada e desplugada numa mesma proposta. Na Tabela 6 foram organizados os instrumentos instrucionais utilizados por estes estudos.

Tabela 6 - Recursos Instrucionais Utilizados na Computação Desplugada

\begin{tabular}{|c|c|c|}
\hline Recursos & Estudos & Frequência \\
\hline Livro Computer Science Unplugged & $\begin{array}{l}1 ; 3 ; 5 ; 8 ; 11 ; 13 ; 18 ; \\
32 ; 34 ; 38 ; 44 ; 47 ; 63 ; \\
65 ; 67 ; 68 ; 70 ;\end{array}$ & 17 \\
\hline Livro Computer Science Unplugged e Scratch & $2 ; 33 ; 41 ;$ & 3 \\
\hline Livro Computer Science Unplugged e Code.org. & 42 & 1 \\
\hline Livro Computer Science Unplugged e robótica & 64 & 1 \\
\hline Livro Computer Science Unplugged e jogos desplugados & 40 & 1 \\
\hline $\begin{array}{l}\text { Livro Computer Science Unplugged e atividades autorais des- } \\
\text { plugadas }\end{array}$ & $4 ; 69 ;$ & 2 \\
\hline Livro Computer Science Unplugged, Code.org e Scratch & 72 & 1 \\
\hline $\begin{array}{l}\text { Livro Computer Science Unplugged, Code.org e atividades } \\
\text { desplugadas autoriais }\end{array}$ & 21 & 1 \\
\hline Code.org & $43 ; 73$ & 2 \\
\hline Code.org e APP Inventor & 46 & 1 \\
\hline Code.org e Scratch & $23 ; 50 ; 59 ;$ & 3 \\
\hline Code.org e LOGO & 17 & 1 \\
\hline Code.org e atividades desplugadas autorais & $56 ; 61 ;$ & 2 \\
\hline Code.org; Scratch, atividades desplugadas autorais & $54 ; 57 ;$ & 2 \\
\hline Code.org, Scratch e Google For Education & 39 & 1 \\
\hline Jogos autoriais & $\begin{array}{l}6 ; 7 ; 14 ; 16 ; 25 ; 27 \\
\quad 28 ; 52 ; 53 ; 71\end{array}$ & 10 \\
\hline Scratch, jogos autoriais & 9 & 1 \\
\hline Atividades desplugadas autorais & $\begin{array}{c}12 ; 19 ; 29 ; 30 ; 31 ; 35 ; \\
36 ; 37 ; 48 ; 49 ; 51 ; 60 ; \\
62 ; 66 ; 75 ;\end{array}$ & 15 \\
\hline Atividades e jogos desplugados autorais & $45 ; 58 ; 69 ;$ & 3 \\
\hline Scratch, atividades desplugadas autorais & $22 ; 24$ & 2 \\
\hline Atividades desplugadas autoriais, aplicativo & 26 & 1 \\
\hline Programaê & 55 & 1 \\
\hline Livro Databases Unplugged & 20 & 1 \\
\hline Livro Infantil & 74 & 1 \\
\hline Poema & 10 & 1 \\
\hline Almanaques & 15 & 1 \\
\hline
\end{tabular}

Fonte: Elaborada pelos autores.

Quanto aos recursos instrucionais utilizados para os estudos com a Computação Desplugada, destaca-se o livro Computer Science Unplugged (BELL; WITTEN; FELLOWS, 2011) como o mais utilizado nos estudos analisados, correspondendo a $36 \%$ ( 27 dos 75) dos trabalhos; outro recurso presente foi o Code.org, em 20\% (15 dos 75) dos trabalhos. Dos estudos analisados, dois relacionaram o livro Computer Science Unplugged e o Code.org ( 2 dos 75 ) na prática pedagógica. Além destes, alguns trabalhos utilizaram outros recursos: $20 \%$ dos estudos utilizaram jogos desplugados autorais (15 dos 75), 
$37,3 \%$ utilizaram atividades desplugadas autorais ( 28 dos 75 ) e 17,3\% utilizaram o Scratch (13 dos 75). Em números menos expressivos, identificamos também o uso de literatura infantil (2 dos 75), plataformas ( 2 dos 75), Logo (1 dos 75), Robótica ( 1 dos 75), Google For Education (1 dos 75), App Inventor (1 dos 75), livro Database Unplugged (1 dos 75).

Para a realização das atividades propostas foram necessárias diferentes ferramentas. $^{7}$ Nos estudos foram listados materiais de papelaria, tais como lápis, tinta, pincel, caneta, folha A4, EVA, cartolina, lousa, fita adesiva, cola, livro, barbante, isopor, tesoura, mapa-múndi, etc.; peças de jogos, como dados, peões, tabuleiro, Torre de Hanói e cartas de baralho; brinquedos; materiais reciclados, como papelão, canos de PVC, garrafas PET, rolos de papel higiênico, etc.; tecnologias digitais, como computador, tablet, smartphone, projetor e Internet; maquiagem e ingredientes para bolo.

Quanto às estratégias de ensino-aprendizagem utilizadas nos estudos analisados, organizamos a Tabela 7, identificando a correspondência e a frequência de estudos.

Tabela 7 - Estratégias de ensino-aprendizagem utilizadas nos estudos

\begin{tabular}{l|c|c}
\hline \multicolumn{1}{c|}{ Estratégias de ensino-aprendizagem } & Estudos & Frequência \\
\hline Baseado em problemas & $1 ; 4 ; 14 ; 15 ; 27 ; 35 ;$ & 5 \\
\hline Dinâmica & $4 ; 20 ; 22 ; 32 ; 42 ; 43 ; 59 ; 62 ; 75 ;$ & 9 \\
\hline Atividades Lúdicas & $17 ; 18 ; 29 ; 30 ; 31 ; 39 ; 42 ; 48 ; 58 ; 63 ; 65 ;$ & 12 \\
\hline Minicurso & $23 ; 33 ; 51 ;$ & 3 \\
\hline Oficina & $2 ; 9 ; 10 ; 34 ; 36 ; 47 ; 49 ; 67 ;$ & 8 \\
\hline Aprendizagem Colaborativa & $11 ; 25 ;$ & 2 \\
\hline Metodologia Modelo ADDIE & 26 & 1 \\
\hline Jogos & $6 ; 7 ; 9 ; 14 ; 16 ; 25 ; 27 ; 28 ; 37 ; 40 ; 44 ; 45 ;$ & 21 \\
\hline Música & $50 ; 52 ; 53 ; 58 ; 60 ; 64 ; 69 ; 71 ; 74 ;$ & 1 \\
\hline Uso de instruções verbais & 19 & 22 \\
\hline
\end{tabular}

Fonte: Elaborada pelos autores.

Quanto às estratégias de ensino-aprendizagem adotadas para a realização das propostas relatadas nos estudos, temos maior concentração no uso de instruções verbais ( 22 dos 75 ), sendo $29,3 \%$ dos estudos; no uso de jogos $28 \%$ ( 21 dos 75 ). Foi possível identificar em 14,6\% (11 dos 75) dos estudos mais de uma estratégia de ensino-aprendizagem, sendo eles: $4 ; 6 ; 7 ; 9 ; 14 ; 25 ; 27 ; 42 ; 43 ; 58 ; 69$. Outras estratégias são identificadas, a saber: aprendizagem baseadas em problemas, 6,6\% (5 dos 75); dinâmicas, $12 \%$ (9 dos 75); atividades lúdicas, 16\% (12 dos 75); minicurso, 4\% (3 dos 75); oficina, 10,6\% (8 dos 75); aprendizagem colaborativa, 2,6\% ( 2 dos 75); metodologia Modelo ADDIE, 1,3\% (1 dos 75 ) e música, $1,3 \%$ ( 1 dos 75$)$.

\section{CONSIDERAÇÕES FINAIS}

\footnotetext{
Neste contexto, ferramenta refere-se a qualquer artefato que se usa para a realização de um trabalho.

Acrônimo de analysis, design, development, implementation e evaluation - análise, design, desenvolvimento, implementação e avaliação.
} 
Este artigo apresentou uma RSL sobre a Computação Desplugada na Educação Básica e no Ensino Superior considerando publicações de 2014 a 2020 nos anais dos eventos SBIE, WIE, WCBIE, RBIE, Renote, WEI, WIT e Anped, com vistas à descrição dos principais elementos que compuseram tais estudos. Em tal procedimento, fomos norteados por quatro questões: Qual o perfil do público-alvo destes estudos? Quais disciplinas estão trabalhando a Computação Desplugada? Quais conceitos são abordados/ensinados por meio da Computação Desplugada? Quais recursos instrucionais e estratégias de ensino/aprendizagem estão sendo utilizados no ensino com Computação Desplugada?

Em nossa amostra, as publicações quanto ao uso da Computação Desplugada em contextos de ensino-aprendizagem aumentaram significativamente a partir de 2017, com predominância no Workshop de Informática na Escola (WIE). As pesquisas analisadas nesta RSL representam 18 Estados brasileiros, com destaque para as regiões Nordeste, Sul e Sudeste, com apenas uma publicação de pesquisa realizada no Estado do Mato Grosso.

O perfil do público-alvo é composto majoritariamente por alunos ou professores da escola pública, com maior concentração no Ensino Fundamental I e II, em contraponto aos poucos estudos encontrados referentes à Educação Infantil e ao Ensino Superior, o que se justifica pelo fato de serem, em grande parte, pesquisas realizadas por acadêmicos ou grupos das universidades públicas brasileiras. Além disso, merecem destaque as amplas discussões que estão ocorrendo no cenário mundial e no âmbito da Computer Science Teacher Association (CSTA), da Sociedade Brasileira de Computação (SBC, 2018) e da Base Nacional Comum Curricular (BNCC) (BRASIL, 2020) quanto à inserção de conceitos da Computação, como ciência, na Educação Básica como elemento fundamental para a vida na sociedade contemporânea.

A Computação Desplugada tem sido trabalhada predominantemente sem relação explícita com disciplinas da BNCC ou com disciplinas específicas da área de Computação, sendo aplicada frequentemente em atividades extraclasse em contexto de ensino-aprendizagem. Se tomarmos apenas as pesquisas vinculadas a disciplinas da BNCC, a Matemática aparece na maioria dos estudos, seja de forma isolada ou interdisciplinar. Esses indicativos levam a refletir sobre como tem sido trabalhado o ensino de conceitos fundamentais da Computação (Pensamento Computacional, Mundo Digital e Cultura Digital) na Educação Básica e como tem sido realizada a inclusão desses conceitos no currículo de todas as áreas da BNCC, não sendo determinada a realização de atividades em contraturno para os trabalhos desses conceitos da Computação.

Os estudos concentram uma maior abordagem na Computação Desplugada sem combinação com atividades plugadas. A maioria relata pesquisas usando atividades do mesmo livro internacional, Computer Science Unplugged, com associação a materiais de baixo custo (papelaria, reciclados, jogos, brinquedos, etc.) e ao uso de instruções verbais. Desta análise elicita-se a hipótese de que, mesmo existindo atividades desplugadas, é importante a conexão delas com outras atividades, que poderiam ser práticas em equipamentos computacionais, em uma continuidade dos percursos educativos.

A quantidade de conceitos da Computação trabalhados nos estudos apresenta uma variação de 1 a 7, com predominância de trabalhos focados em 1 ou 2 conceitos, destacando-se os de Algoritmo, Lógica de Programação e Números Binários. Observan- 
do que o maior número de estudos ocorreu na Educação Básica e diante das referências apresentadas pela BNCC (BRASIL, 2020) e por diretrizes da SBC (2018) para o trabalho na Educação Básica, identificamos a necessidade de realização de atividades com enfoque nos eixos Pensamento Computacional, Mundo Digital e Cultura Digital.

Diante dos estudos analisados, identificamos que apenas um estudo (o de número 29) foi realizado remotamente, em 2020, devido à pandemia. Os demais (74 estudos) ocorreram de forma presencial. Apesar de as atividades de CD terem sido projetadas para uso presencial, acreditamos que a adaptação delas para o ensino on-line é uma possibilidade de prática e pesquisa que merece atenção, para incentivo ao Pensamento Computacional. Neste modelo, há possibilidade de trabalhar em contraturno escolar na forma de oficinas, sem a necessidade de o estudante sair de casa, considerando a pandemia da Covid-19, com severas limitações às aulas presenciais. Em disciplinas como a Matemática, que muitas vezes demandam reforço escolar, essa seria uma estratégia interessante para as escolas.

Nesta RSL, buscamos identificar e descrever em qual cenário a CD está sendo trabalhada e quais os recursos e conceitos empregados, o que a difere das RSLs encontradas durante a seleção dos estudos. Estas se limitavam ao emprego da CD para o ensino de Programação, às estratégias de avaliação (RODRIGUES; ARANHA; SILVA (2018), aos níveis de ensino e à efetivação e avaliação dessas pesquisas (SANTOS et al, 2018). Neste sentido, ressalta-se que os achados desta revisão sistemática podem servir como orientação aos docentes que pretendem utilizar a $C D$ e/ou aqueles que intentam pesquisar na área, apresentando uma análise de tendências identificadas em artigos de distintos veículos. Apesar do considerável número de eventos analisados e da relação deles com a temática, essa RSL pode ser estendida, incluindo outros eventos nacionais e, inclusive, internacionais, visto que a CD pode estar sendo utilizada em outras áreas.

Por fim, destacamos que esta pesquisa não teve a intenção de esgotar as análises dos dados apresentados, pois considera-se que futuros estudos poderão vir complementar os achados aqui identificados, sobretudo aqueles que não foram abordados neste trabalho. $\mathrm{O}$ aperfeiçoamento e atualização da RSL deve ser realizado anualmente, a fim de analisarmos o cenário e novos resultados que podem ser obtidos aumentando-se o período recoberto pelas pesquisas, diversificando-se as bases de dados consultadas ou adicionando-se novos descritores de busca.

\section{AGRADECIMENTOS}

Esta pesquisa contou com o apoio do Conselho Nacional de Desenvolvimento Científico e Tecnológico - CNPq - e da Secretaria de Estado de Educação de Mato Grosso-Seduc.

\section{REFERÊNCIAS}

ALVES, E. S. et al. A contribuição do Projeto Berçário de Hackers na alfabetização matemática de crianças em fase pré-operatória. In: WORKSHOP DE INFORMÁTICA NA ESCOLA, 2017. p. 1.129-1.133.

AMIN, F. et al. Oficina Gurias na Computação: três horas de imersão feminina na área da computação discutidas em detalhes. In: WOMEN IN INFORMATION TECHNOLOGY (WIT), 13., 2019. Belém. Anais [...]. Porto Alegre: Sociedade Brasileira de Computação, jul. 2019. p. 149-153. 
AMARAL, Marília Abrahão et al. Introducing Computer Science to Brazilian Girls in Elementary School through $\mathrm{HCl}$ Concepts. In: INTERNATIONAL CONFERENCE OF DESIGN, USER EXPERIENCE, AND USABILITY. Springer, Cham, 2015. p. 141-152.

ARAÚJO, D. da C. et al. O ensino de computação na educação básica apoiado por problemas: práticas de licenciados em computação. In: WORKSHOP SOBRE EDUCAÇÃO EM COMPUTAÇÃO (WEI), 2015. 23., 2015, Recife. Anais [...]. Porto Alegre: Sociedade Brasileira de Computação, 2015. p. 130-139.

BARBOSA, A. V. de S. et al. O ensino de conceitos computacionais para alunos do ensino médio: relato de experiência de uma gincana e das estratégias utilizadas pelos alunos na resolução das atividades desplugadas. In: WORKSHOP SOBRE EDUCAÇÃO EM COMPUTAÇÃO (WEI), 23., 2015, Recife. Anais [...]. Porto Alegre: Sociedade Brasileira de Computação, 2015. p. 120-129.

BARCELOS, T. S. SILVEIRA, I. F. Teaching computational thinking in initial series an analysis of the confluence among mathematics and computer sciences in elementary education and its implications for higher education. In: CONFERENCIA LATINOAMERICANA EN INFORMATICA (CLEI), 38., 2012, Medellin. p. 1-8.

BARROSO, Ruan Soares; SANTOS, Ana Rita de Souza dos; MACHADO, Veruska Ribeiro. Loop - Tabuleiro lógico: uma proposta de ensino com computação desplugada. In: WORKSHOP DE INFORMÁTICA NA ESCOLA (WIE). 25., 2019, Brasília. Anais [...]. Porto Alegre: Sociedade Brasileira de Computação, 2019. p. 628-633. BELL, T.; WITTEN, I. H.; FELLOWS, M. Computer Science Unplugged. 2011. Disponível em: https://classic. csunplugged.org/wp-content/uploads/2014/12/CSUnpluggedTeachers-portuguese-brazil-feb-2011.pdf. Acesso em: 4 nov. 2019.

BERARDI, Rita C. G. et al. Oficina de banco de dados com aprendizado cinestésico para meninas do Ensino Médio. In: WORKSHOP DE INFORMÁTICA NA ESCOLA (WIE), 25., 2019, Brasília. Anais [...]. Porto Alegre: Sociedade Brasileira de Computação, 2019. p. 345-354.

BERTO, L. M.; ZAINA, L. A. M.; SAKATA; T. C. Metodologia para ensino do pensamento computacional para crianças baseada na alternância de atividades plugadas e desplugadas. In: Revista Brasileira de Informática na Educação (RBIE), v. 27, n. 2, 2019. p. 1-22.

BEZERRA, Fabio. Bem mais que os bits da computação desplugada. In: WORKSHOP DE INFORMÁTICA NA ESCOLA (WIE), 2014. Dourados/MS, p. 116-125.

BIM, S. A. et al. A vida de Ada Lovelace em um circuito de atividades desplugadas. (2019). In: WOMEN IN INFORMATION TECHNOLOGY (WIT), 13., 2019. Belém. Anais [...]. Porto Alegre: Sociedade Brasileira de Computação, jul. 2019. p. 189-193.

BRACKMANN, Christian Puhlmann. Desenvolvimento do pensamento computacional através de atividades desplugadas na educação básica. 2017. 226 f. Tese (Doutorado) - Universidade Federal do Rio Grande do Sul, Centro de Estudos Interdisciplinares em Novas Tecnologias na Educação, Programa de Pós-Graduação em Informática na Educação, Porto Alegre, RS, 2017.

BRACKMANN, C. P. et al. Pensamento computacional desplugado: ensino e avaliação na educação primária da Espanha. In: WORKSHOPS DO CONGRESSO BRASILEIRO DE INFORMÁTICA NA EDUCAÇÃO, 2017. Brasília-DF, p. 982-991.

BRASIL. Ministério da Educação. Base Nacional Comum Curricular - BNCC. Disponível em: http://basenacionalcomum.mec.gov.br/. Acesso em: 28 maio 2020.

BULCÃO, J. da S. B. et al. Computação desplugada alinhada aos descritores de matemática do Saeb: um relato de experiência. In: WORKSHOPS DO CONGRESSO BRASILEIRO DE INFORMÁTICA NA EDUCAÇÃO. 2019. Brasília-DF, p. 407-416.

BULHÕES, D. B. et al. O uso da computação desplugada no processo de ensino-aprendizagem de alunos do curso Técnico em Informática. In: SIMPÓSIO BRASILEIRO DE INFORMÁTICA NA EDUCAÇÃO, 2019. Brasília-DF, p. 932-941.

CAMPOS et al. Organização de Informações via pensamento computacional: relato de atividade aplicada no Ensino Fundamental. In: WORKSHOP DE INFORMÁTICA NA ESCOLA, 2014. Dourados/MS, p. 390-399.

CASTILHO, Marcos Alexandre; GREBOGY, Elaine Cristina; SANTOS, Icléia. O pensamento computacional no Ensino Fundamental I. In: WORKSHOP DE INFORMÁTICA NA ESCOLA, 25., 2019, Brasília. Anais [...]. Porto Alegre: Sociedade Brasileira de Computação, 2019. p. 461-470.

CASTRO, A. A. Cursos de revisão sistemática e metanálise. São Paulo: LEDDIS; Unifesp, 2001. Disponível em: http://www.usinadepesquisa.com/metodologia/wp-content/uploads/2010/08/meta1.pdf. Acesso em: 5 set. 2020.

CODE.ORG. What is Code.org? 2013. Disponível em: https://support.code.org/hc/en-us/articles/ 204784827-What-is-Code-org-. Acesso em: 18 out. 2019. 
COSTA, Karine P. C. da; AZEVEDO, Matheus S.; MADEIRA, Charles A. G. Facilitando o uso do Scratch por meio de atividade desplugada que introduz o estudo do plano cartesiano. In: WORKSHOPS DO CONGRESSO BRASILEIRO DE INFORMÁTICA NA EDUCAÇÃO, 2018. Brasília-DF, p. 778-787.

CREMA, C. et al. Computação desplugada na Udesc Portas Abertas. In: Renote - Revista Novas Tecnologias na Educação, v. 17, n. 3, dez. 2019.

CSUNPLUGGED. Computer Science Without a Computer. 2020. Disponível em: https://www.csunplugged. org/en/. Acesso em: 15 maio 2020.

CSTA. Computer Science Teacher Association. K-12 Computer Science Standards - Revised 2011 - The CSTA Standards Task Force. New York: Association for Computing Machinery, 2011.

CSTA; ISTE. Computer Science Teacher Association; International Society for Technology in Education. Computational Thinking: leadership toolkit. 2011. Disponível em: https://csta.acm.org/Curriculum/sub/ CurrFiles/471.11CTLeadershiptToolkit-SP-vF.pdf. Acesso em: 8 out. 2019.

CUNHA, Felipe Oliveira Miranda; NASCIMENTO, Cristiane Ribeiro do. Uma abordagem baseada em robótica e computação desplugada para desenvolver o pensamento computacional na educação básica. In: SIMPÓSIO BRASILEIRO DE INFORMÁTICA NA EDUCAÇÃO. 2018. Fortaleza/CE, p. 1.845-1.849.

DALL AGNOL, A.; GUSBERTI, C.; BERTAGNOLLI, S. C. O ensino de pensamento computacional através de um jogo de tabuleiro em ambiente desplugado: relato de experiência de formação docente. In: Renote Revista Novas Tecnologias na Educação, v. 18, n. 1, jul. 2020.

DRESCH, Aline; LACERDA, Daniel P.; ANTUNES JUNIOR, José Antônio V. Design Science Research: método de pesquisa para o avanço da ciência e tecnologia. Porto Alegre: Bookman, 2015.

FARIAS, C. M. d. et al. Estimulando o pensamento computacional: uma experiência com ScratchJr. In: WORKSHOP DE INFORMÁTICA NA ESCOLA, 25., 2019, Brasília/DF. Anais [...]. Porto Alegre: Sociedade Brasileira de Computação,2019. p. 197-206.

FERREIRA et al. Experiência prática interdisciplinar do raciocínio computacional em atividades de computação desplugada na educação básica. In: WORKSHOP DE INFORMÁTICA NA ESCOLA, 2015. Maceió-AL, p. 256-265.

FIGUEIREDO, L. et al. Código X em casa: um relato de experiência sobre o ensino remoto de computação desplugada para meninas em situação de vulnerabilidade socioeconômica, em tempos de distanciamento social. In: WORKSHOP DE INFORMÁTICA NA ESCOLA (WIE), 26., Natal, nov. 2020. p. 279-288.

FRANÇA, Rozelma Soares de; TEDESCO, Patrícia Cabral de Azevedo Restelli. Sertão. Bit: um livro-jogo de difusão do pensamento computacional. In: WORKSHOPS DO CONGRESSO BRASILEIRO DE INFORMÁTICA NA EDUCAÇÃO. 2019. Brasília-DF, p. 278-287.

GALVÃO, E. M. P. et al. Uma proposta transversal ao ensino de pensamento computacional e de ciências no Ensino Fundamental I. In: WORKSHOPS DO CONGRESSO BRASILEIRO DE INFORMÁTICA NA EDUCAÇÃO, 2019. Brasília-DF, p. 357-366.

GERALDES, Wendell Bento; MARTINS, Ernane Rosa; AFONSECA, Ulisses Rodrigues. Uma experiência em ensino de programação de computadores com alunos da rede pública usando a linguagem Scratch. In: WORKSHOP DE INFORMÁTICA NA ESCOLA, 2019. Brasília-DF, p. 129-137.

GUARDA, Graziela Ferreira; GONÇALVES, Caroline dos Santos; CUNHA, Lídia Raquel Rocha. Jogo corrida das frações - ludicidade e pensamento computacional. In: WORKSHOP DE INFORMÁTICA NA ESCOLA, 2019. Brasília-DF, p. 19-28.

HINTERHOLZ, Lucas Tadeu; CRUZ, Marcia Elena Kniphoff da. Desenvolvimento do pensamento computacional: um relato de atividade junto ao Ensino Médio, através do Estágio Supervisionado em Computação III. In: WORKSHOP DE INFORMÁTICA NA ESCOLA, 2015. Maceió-AL, p. 137-146.

KOHLER, L. P. de A. et al. Circuito de quatro estações aplicando a computação desplugada. In: WORKSHOP DE INFORMÁTICA NA ESCOLA, 2019a. Brasília-DF, p. 1.369-1.373.

KOHLER, L. P. de A. et al. Uso da metodologia de rotação por estações com a Computação Desplugada. In: WORKSHOPS DO CONGRESSO BRASILEIRO DE INFORMÁTICA NA EDUCAÇÃO, 2019b. Brasília-DF, p. 427436.

KOLOGESKI, A. L. et al. Tecnologia na educação: o pensamento computacional e a computação desplugada como forma de inclusão digital. In: WORKSHOPS DO CONGRESSO BRASILEIRO DE INFORMÁTICA NA EDUCAÇÃO, 2019. Brasília-DF, p. 288-297.

KOSCIANSKI, André; GLIZT, Fabiana Rodrigues de Oliveira. O Pensamento computacional nos anos iniciais do Ensino Fundamental. In: Renote - Revista Novas Tecnologias na Educação, v. 15, n. 2, dez. 2017. 
LIMA, A. C. et al. Uma oficina para ensino de algoritmos paralelos por meio de computação desplugada. In: WORKSHOPS DO CONGRESSO BRASILEIRO DE INFORMÁTICA NA EDUCAÇÃO, 2018. Fortaleza-CE, p. 619-628.

LOPES, Alexandre D.; OHASHI, Andréa G. R. Estimular o pensamento computacional através da computação desplugada aos alunos do Ensino Fundamental. In: WORKSHOP DE INFORMÁTICA NA ESCOLA, 2019. Brasília-DF, p. 424-433.

LOPES, A. F.; SANTANA, T. S.; BRAGA, A. H. O ensino de pensamento computacional por meio de jogos desplugados e olimpíadas científicas: um relato de experiência nos anos finais do Ensino Fundamental. In: WORKSHOP SOBRE EDUCAÇÃO EM COMPUTAÇÃO (WEI), 28., Cuiabá, jun. 2020. p. 96-100.

MACIEL, Cristiano; BIM, Sílvia Amélia; DA SILVA FIGUEIREDO, Karen. Digital girls program: disseminating computer science to girls in Brazil. In: INTERNATIONAL WORKSHOP ON GENDER EQUALITY IN SOFTWARE ENGINEERING, 1., 2018. Proceedings [...]. Gotemburgo, Suécia, 2018. p. 29-32.

MACIEL, Cristiano; BIM, Silvia Amélia; BOSCARIOLI, Clodis. A fantástica fábrica de chocolate: levando o sabor de IHC para meninas do ensino fundamental. In: IHC (Companion), Cuiabá-MT, 2012, p. 27-28.

MARQUES, Wagner dos Santos; SOUZA, Paulo Silas Severo de; MOMBACH, Jaline Gonçalves. Pensar para programar: projeto de ensino no curso técnico em informática. In: WORKSHOP SOBRE EDUCAÇÃO EM COMPUTAÇÃO, 25., 2017, São Paulo. Anais [...]. Porto Alegre: Sociedade Brasileira de Computação,2017. p. 2.110-2.019.

MARQUES, Samanta Ghisleni; CRUZ, Marcia E. Jochims Kniphoff da; SCHULZ, Felipe. Formação continuada de licenciados em computação para trabalho com computação na escola. In: WORKSHOPS DO CONGRESSO BRASILEIRO DE INFORMÁTICA NA EDUCAÇÃO, 2019. Brasília-DF, p. 31-40.

MARQUIORI, Vânia Silvares; OLIVEIRA, Márcia Gonçalves de. O pensamento computacional na compreensão de problemas do cotidiano feminino para o letramento em programação. In: WORKSHOPS DO CONGRESSO BRASILEIRO DE INFORMÁTICA NA EDUCAÇÃO, 2019. Brasília-DF, p. 495-504.

MARINHO, A. R. da S. et al. Relato de experiência vivenciada no Pibid sobre a utilização da computação desplugada, a hora do código e do Scratch no Ensino Médio. In: WORKSHOP SOBRE EDUCAÇÃO EM COMPUTAÇÃO, 2018. Natal-RN, p. 306-315.

MARTINHAGO, A. Z. et al. Computação Desplugada no ensino de banco de dados na educação superior. In: WORKSHOP SOBRE EDUCAÇÃO EM COMPUTAÇÃO, 22., 2014, Brasília. Anais [...]. Porto Alegre: Sociedade Brasileira de Computação, 2014.

MEDEIROS, S. et al. Ensino de algoritmos através de poesia compilada e computação desplugada: relato de experiência com alunos de Ensino Fundamental. In: WORKSHOP DE INFORMÁTICA NA ESCOLA, 24., 2018, Fortaleza, CE. Anais [...]. Porto Alegre: Sociedade Brasileira de Computação, 2018. p. 381-390.

MEDEIROS, S. R. S. Contextualizando as atividades desplugadas para aumentar o engajamento das crianças. In: SIMPÓSIO BRASILEIRO DE INFORMÁTICA NA EDUCAÇÃO (SBIE), 31., Natal, nov. 2020. p. 1.5431.552.

MELGAÇO, Alejandro Cancela; DIAS, Josualdo. Desenvolvimento e aplicação de práticas desplugadas para o ensino de Redes de Computadores. In: WORKSHOP DE INFORMÁTICA NA ESCOLA, 25., 2019, Brasília. Anais [...]. Porto Alegre: Sociedade Brasileira de Computação, 2019. p. 481-490.

MORANDI, M. I. W. M.; CAMARGO, L. F. R. Revisão sistemática da literatura. In: DRESCH, Aline; LACERDA, Daniel P.; ANTUNES JUNIOR, José Antônio V. Design Science Research: método de pesquisa para o avanço da ciência e tecnologia. Porto Alegre: Bookman, 2015.

MOREIRA, Jussara Adolfo; MONTEIRO, Willmara Marques. O uso da computação desplugada em um contexto de gamificação para o ensino de estrutura de dados. In: Renote - Revista Novas Tecnologias na Educação, v. 16, n. 2, dez. 2018.

PASSOS, J. et al. Abrindo mentes com a computação desplugada: uma experiência com meninas de oitavo e nono anos. In: WOMEN IN INFORMATION TECHNOLOGY (WIT), 14., 2020, Cuiabá. Anais [...]. Porto Alegre: Sociedade Brasileira de Computação, jun. 2020. p. 164-168

PEREIRA, Francisco T. S. S; ARAÚJO, Luis Gustavo J.; BITTENCOURT, Roberto A. Intervenções de Pensamento computacional na educação básica através de computação desplugada. In: WORKSHOP DE INFORMÁTICA NA ESCOLA, 2019. Brasília-DF, p. 315-324.

PINHEIRO, J. V. et al. Programa\{ação\} - Atividades lúdicas para ensino de programação em escolas públicas. In: WORKSHOP SOBRE EDUCAÇÃO EM COMPUTAÇÃO (WEI), 27., 2019, Belém. Anais [...]. Porto Alegre: Sociedade Brasileira de Computação, 2019.

PINHO, G. et al. Pensamento Computacional no Ensino Fundamental: Relato de Atividade de Introdução a Algoritmos. (2016). In: Anais Workshop de Informática na Escola. Pg. 261-270. 
PIRES, F. et al. Incentivos ao desenvolvimento do pensamento computacional no Ensino Médio: aprendendo a programar. In: WORKSHOPS DO CONGRESSO BRASILEIRO DE INFORMÁTICA NA EDUCAÇÃO, 2019. Brasília-DF, p. 495-504.

POLYA, G. How to solve it: a new aspect of mathematical method. Princeton: Princeton University Press, 2004.

PROGRAMAÊ! Programaê! Disponível em: http://programae.org.br/. Acesso em: 17 out. 2019.

RAIOL, A. A. et al. Experiências de ensino da computação desplugada em diferentes séries da educação fundamental maior. In: WORKSHOP SOBRE EDUCAÇÃO EM COMPUTAÇÃO (WEI), 24., 2016, Porto Alegre. Anais [...]. Porto Alegre: Sociedade Brasileira de Computação, 2016. p. 2.146-2.155.

REIS, R. C. D. et al. Relato de experiência sobre o uso da computação desplugada associada a uma teoria de aprendizagem colaborativa. In: WORKSHOP DE INFORMÁTICA NA ESCOLA, 24., 2018, Fortaleza, CE. Anais [...]. Porto Alegre: Sociedade Brasileira de Computação,2018. p. 166-175.

RODRIGUES, Guilherme Carvalho; SAUSA, Laureane Pereira de. $O$ ensino de pensamento computacional como inclusão tecnológica e motivação de crianças. In: SIMPÓSIO BRASILEIRO DE INFORMÁTICA NA EDUCAÇÃO, 2017. Recife-PE, p. 1.784-1.786.

RODRIGUES, Ariane N.; LOPES, Renato H. de Oliveira. Proposta e adaptação de atividades desplugadas para o ensino de computação na educação básica. In: WORKSHOP SOBRE EDUCAÇÃO EM COMPUTAÇÃO (WEI), 25., 2017, São Paulo. Anais [...]. Porto Alegre: Sociedade Brasileira de Computação, 2017. p. 2.2272.236 .

RODRIGUES, Sebastião R. C.; ARANHA, Eduardo; SILVA, Thiago R. da. Computação desplugada no ensino de programação: uma revisão sistemática da literatura. In: SIMPÓSIO BRASILEIRO DE INFORMÁTICA NA EDUCAÇÃO, 2018. Fortaleza-CE, p. 417-426.

RODRIGUES, Guilherme Carvalho; BRAGA, Rafael Debastiani do Carmo; AMORIM, Thiago Batista. Criptografia e segurança Web: um relato de experiência do ensino de conceitos computacionais para crianças. In: WORKSHOP DE INFORMÁTICA NA ESCOLA, 25., 2019, Brasília. Anais [...]. Porto Alegre: Sociedade Brasileira de Computação, 2019. p. 1.099-1.103.

SANTANA, Beatriz Silva de; PEREIRA, Claudia Pinto. Aproximação de alunas do ensino básico do pensamento computacional: relato de experiência de uma oficina de eletrônica. In: WORKSHOP DE INFORMÁTICA NA ESCOLA, 25., 2019, Brasília. Anais [...]. Porto Alegre: Sociedade Brasileira de Computação, 2019. p. 69-78.

SANTANA, Bianca L.; ARAÚJO, Luis Gustavo J.; BITTENCOURT, Roberto A. Computação e eu: uma proposta de educação em computação para o sexto ano do Ensino Fundamental II. In: WORKSHOP SOBRE EDUCAÇÃO EM COMPUTAÇÃO (WEI), 27., 2019, Belém. Anais [...]. Porto Alegre: Sociedade Brasileira de Computação, 2019.

SANTOS, A.; SANTANA, K. C.; PEREIRA, C. P. Computação divertida: o ensino da computação através das estratégias de computação desplugada para crianças do ensino fundamental. In: SIMPÓSIO BRASILEIRO DE INFORMÁTICA NA EDUCAÇÃO (SBIE), 31. Natal, nov. 2020. p. 1.443-1.452.

SANTOS, Euma Silva; VERA, William Fabian Machado; MATOS, Ecivaldo de Souza. A percepção dos professores sobre a prática da interdisciplinaridade no ensino de computação para escolares. In: WORKSHOP SOBRE EDUCAÇÃO EM COMPUTAÇÃO (WEI), 25., 2017, São Paulo. Anais [...]. Porto Alegre: Sociedade Brasileira de Computação, 2017. p. 2.120-2.029.

SANTOS, Wilk Oliveira dos et al. Computação desplugada: um mapeamento sistemático da literatura nacional. In: Renote - Revista Novas Tecnologias na Educação, v. 16, n. 2, dez. 2018.

SANTOS, G. et al. Proposta de atividade para o quinto ano do Ensino Fundamental: algoritmos desplugados. In: WORKSHOP DE INFORMÁTICA NA ESCOLA, 2015. Maceió-AL, p. 246-255.

SANTOS, Cicero G.; NUNES, Maria Augusta S. N. Abordagem desplugada para o estímulo do pensamento computacional de estudantes do Ensino Fundamental com histórias em quadrinhos. In: WORKSHOP DE INFORMÁTICA NA ESCOLA, 25., 2019, Brasília. Anais [...]. Porto Alegre: Sociedade Brasileira de Computação, 2019. p. 570-579.

SASSI, S. B.; MACIEL, C.; PEREIRA, V. C. Experiência com atividades desplugadas do Code.org na disciplina de língua estrangeira de uma escola estadual. In: WORKSHOP SOBRE EDUCAÇÃO EM COMPUTAÇÃO (WEI), 28, Cuiabá, jun. 2020. p.131-135.

SBC. Sociedade Brasileira de Computação. Nota técnica da Sociedade Brasileira de Computação sobre a BNCC-EF e a BNCC-EM. 2018. Disponível em: https://www.sbc.org.br/institucional-3/cartas-abertas/ summary/93-cartas-abertas/1197- nota-tecnica-sobre-a-bncc-ensino-medio-e-fundamental, Acesso: 17 abr. 2020. 
SCRATCH. Scratch - Imagine, Program, Share. 2017. Disponível em: https://scratch.mit.edu/. Acesso em: 17 out. 2019.

SILVA, V., SOUZA, A., MORAIS, D. Pensamento computacional no ensino de computação em escolas: um relato de experiência de estágio em licenciatura em computação em escolas públicas. In: CONGRESSO REGIONAL SOBRE TECNOLOGIAS NA EDUCAÇÃO, 2016. p. 324-325.

SILVA, Leonardo S. e.; CAVALCANTI, Elmano R. Avaliação do estado de fluxo e do aprendizado em atividades desplugadas no ensino do pensamento computacional com estudantes do Ensino Médio. In: SIMPÓSIO BRASILEIRO DE INFORMÁTICA NA EDUCAÇÃO, 2018. p. 1.746-1.750.

SILVA, Débora Juliane Guerra Marques da; GUARDA, Graziela Ferreira; GOULART, Ione Ferrarini. CriptoLab: um game baseado em computação desplugada e criptografia. In: WORKSHOP SOBRE EDUCAÇÃO EM COMPUTAÇÃO (WEI), 26., 2018, Natal. Anais [...]. Porto Alegre: Sociedade Brasileira de Computação, 2018. p. 49-58.

SILVA, T. R. da; ARAUJO, G. G. de; ARANHA, E. H. da S. Oficinas itinerantes de Scratch e computação desplugada para professores como apoio ao ensino de computação - um relato de experiência. In: WORKSHOP DE INFORMÁTICA NA ESCOLA, 2014. Dourados-MS, p. 380-389.

SILVA, Vlademir; SILVA, Klebson; FRANÇA, Rozelma Soares de. Pensamento Computacional na formação de professores: experiências e desafios encontrados no ensino da computação em escolas públicas. In: WORKSHOP DE INFORMÁTICA NA ESCOLA, Recife-PE, p. 805-814.

SILVA, Andreia Pinheiro dos Santos; FRANCO, João Silvestre dos Santos; JUNIOR, Jorge Costa Leite. Desenvolvimento do pensamento computacional e discussões sobre representação feminina na computação: um estudo de caso. In: WORKSHOPS DO CONGRESSO BRASILEIRO DE INFORMÁTICA NA EDUCAÇÃO, 2017. Recife-PE, p. 1.111-1.120.

SILVA, Natália Francisco da; SANTOS, Igor Brito dos; ORLEANS, Luís Fernando. Ensino inclusivo de pensamento computacional: um relato de experiência. In: WORKSHOP SOBRE EDUCAÇÃO EM COMPUTAÇÃO (WEI), 27., 2019, Belém. Anais [...]. Porto Alegre: Sociedade Brasileira de Computação, 2019.

SILVA, V. L. et al. Algo+ritmo: uma proposta desplugada com a música para auxiliar no desenvolvimento do pensamento computacional. In: WORKSHOP DE INFORMÁTICA NA ESCOLA, 25., 2019, Brasília. Anais [...]. Porto Alegre: Sociedade Brasileira de Computação, 2019. p. 404-413.

SILVA, Francisco B. da; GUIMARÃES, Kelinne O.; JUNIOR, Moisés L. F. L. Introdução à ciência da computação com computação desplugada no Ensino Fundamental II. In: WORKSHOP DE INFORMÁTICA NA ESCOLA, 25., 2019, Brasília. Anais [...]. Porto Alegre: Sociedade Brasileira de Computação, 2019. p. 1.059-1.063. SILVA, Débora Juliane Guerra Marques da; GUARDA, Graziela Ferreira. CriptoData: ensino de criptografia via computação desplugada. In: WORKSHOPS DO CONGRESSO BRASILEIRO DE INFORMÁTICA NA EDUCAÇÃO, 2019. Brasília-DF, p. 248-257.

SILVA, A. V. B. M. et al. Manas digitais: um relato sobre ensino de programação em escolas públicas no Estado do Pará. In: WORKSHOPS DO CONGRESSO BRASILEIRO DE INFORMÁTICA NA EDUCAÇÃO, 2019. Brasília-DF, p. 367-376.

SILVA, S. D. M. et al. Computação desplugada como instrumento avaliativo no Ensino Superior: um relato de experiência. In: WORKSHOP DE INFORMÁTICA NA ESCOLA (WIE), 26, Natal, nov. 2020. p. 121-130.

SIMAS, Emanuelle M. P.; MOTTA, Claudia L. R. da. Pensamento computacional desplugado e transtornos do aprendizado: experiência na educação básica. In: WORKSHOP DE INFORMÁTICA NA ESCOLA, 25., 2019, Brasília. Anais [...]. Porto Alegre: Sociedade Brasileira de Computação, 2019. p. 1.329-1.333.

SOUSA, B. et al. Robótica educacional e computação desplugada: experiência em oficinas para calouros. In: WORKSHOPS DO CONGRESSO BRASILEIRO DE INFORMÁTICA NA EDUCAÇÃO, 2018. Fortaleza-CE, p. 540-549.

SOUZA, Jessica Silva de; LOPES, Alba Sandyra Bezerra. Estimulando o pensamento computacional e o raciocínio lógico no Ensino Fundamental por meio da OBI e computação desplugada. In: SIMPÓSIO BRASILEIRO DE INFORMÁTICA NA EDUCAÇÃO, 2018. Fortaleza-CE, p. 1.893-1.897.

VALENTE, J. A. Integração do pensamento computacional no currículo da educação básica: diferentes estratégias usadas e questões de formação de professores e avaliação do aluno. Revista e-Curriculum, v. 14, n. 3, 2016.

WERLICH, C. et al. Pensamento computacional no Ensino Fundamental I: um estudo de caso utiliza computação desplugada. In: WORKSHOPS DO CONGRESSO BRASILEIRO DE INFORMÁTICA NA EDUCAÇÃO, 2018. Fortaleza-CE, p. 719-728.

WERLICH, C. et al. Objetos de aprendizagem plugados e desplugados: um estudo de caso com ordenação alfabética. In: WORKSHOP DE INFORMÁTICA NA ESCOLA, 2019. Brasília-DF, p. 49-58. 